\title{
Arm length is associated with type 2 diabetes mellitus in Japanese-Americans
}

\author{
M. M. Smits • E. J. Boyko • K. M. Utzschneider • \\ D. L. Leonetti • M. J. McNeely • S. Suvag • \\ L. A. Wright $\cdot$ W. Y. Fujimoto $\cdot$ S. E. Kahn
}

Received: 3 December 2011 / Accepted: 23 January 2012/Published online: 24 February 2012

(C) Springer-Verlag (outside the USA) 2012

\begin{abstract}
Aims/hypothesis The aim of the study was to examine the association of type 2 diabetes mellitus with arm length as a marker for early life environment and development.

Methods This was a cross-sectional analysis of 658 secondand third-generation Japanese-Americans (349 men and 309 women). Different arm length (total, upper and forearm length) and leg length (total and lower leg length) measurements were performed. Type 2 diabetes was defined by the use of hypoglycaemic medication, fasting plasma glucose (FPG) $\geq 7 \mathrm{mmol} / 1$ or glucose at $2 \mathrm{~h} \geq 11.1 \mathrm{mmol} / \mathrm{l}$ during an OGTT. Persons meeting the criteria for impaired glucose tolerance were excluded from these analyses (FPG $<7 \mathrm{mmol} / \mathrm{l}$ and $2 \mathrm{~h}$ glucose during an OGGT $<11.1$ but $\geq 7.8 \mathrm{mmol} / \mathrm{l}$ ). Multivariable logistic regression was used to estimate associations between prevalence of diabetes and limb length while adjusting for possible confounders.
\end{abstract}

M. M. Smits • K. M. Utzschneider • S. Suvag $\cdot$ L. A. Wright $•$

W. Y. Fujimoto $\cdot$ S. E. Kahn

Division of Metabolism, Endocrinology and Nutrition,

Department of Medicine, University of Washington,

Seattle, WA, USA

M. M. Smits • E. J. Boyko $(\bowtie) \cdot$ K. M. Utzschneider • S. Suvag •

L. A. Wright $\cdot$ S. E. Kahn

VA Puget Sound Health Care System (S-152E),

1660 South Columbian Way,

Seattle, WA 98108, USA

e-mail: eboyko@u.washington.edu

E. J. Boyko

Division of General Internal Medicine, Department of Medicine, University of Washington,

Seattle, WA, USA

D. L. Leonetti $\cdot$ M. J. McNeely

Department of Anthropology, University of Washington,

Seattle, WA, USA
Results A total of 145 individuals had diabetes. On univariate analysis, arm and leg length were not associated with diabetes. After adjustment for age, sex, computed tomography-measured intra-abdominal fat area, height, weight, smoking status and family history of diabetes, total arm length and upper arm length were inversely related to diabetes (OR for a 1 SD increase $0.49,95 \%$ CI $0.29,0.84$ for total arm length, and OR $0.56,95 \%$ CI $0.36,0.87$ for upper arm length). Forearm length, height and leg length were not associated with diabetes after adjustment for confounding variables.

Conclusions/interpretation Our findings of associations between arm lengths and prevalence of type 2 diabetes supports a role for factors that determine bone growth or their correlates in the development of this condition.

Keywords Anthropometry · Japanese-Americans · Thrifty phenotype hypothesis - Type 2 diabetes - Visceral fat

$\begin{array}{ll}\text { Abbreviations } \\ \text { FPG } & \text { Fasting plasma glucose } \\ \text { IAF } & \text { Intra-abdominal fat } \\ \text { IGT } & \text { Impaired glucose tolerance } \\ \text { JACDS } & \text { Japanese-American Community Diabetes Study }\end{array}$

\section{Introduction}

Several studies have shown an inverse relationship between height and type 2 diabetes [1-3]. Recent reports have shown that leg length is the key component of this association since it was related to type 2 diabetes, whereas trunk length was not [3-5]. It has been hypothesised that short adult leg length, in particular short femur length, is a marker of poor 
environmental conditions in early life, both in utero and during early childhood [6-9]. Previous work has shown that adult leg length is sensitive to breastfeeding and energy intake in early childhood, the period during which the legs grow fastest [8], and that leg length is decreased in chronic childhood illnesses [7]. It has also been shown that leg length is associated with psychological stress during childhood [10]. The role of early life diet on leg length is, however, debatable as it was recently reported that nutritional supplementation during pregnancy and early infancy in an undernourished population did not change relative leg length [11].

One potential explanation for the observed associations between limb length and diabetes is that the former serves as a marker of nutritional state and stress during the early phases of life, when bone development and growth occur. The 'thrifty phenotype hypothesis' posits that an adverse early life environment influences the development of beta cells (in terms of both mass and function) and insulin resistance, making an individual more prone to developing diabetes in later life [12]. Thus, limb length and height may reflect early life development and serve as a means to indirectly test the thrifty phenotype hypothesis.

Arm length shows roughly the same growth pattern as leg length, with growth in utero and spurts during the first 2 years of life and during puberty [13-15]. One can therefore envision that arm length also may be determined by environmental factors. Indeed, it has been shown that arm length is associated with environmental factors during infancy, such as lead poisoning and economic status, and may thus be a marker of early life deprivation or stress [16, 17].

Given these observations, we undertook a study to test the hypothesis that arm length is inversely associated with the prevalence of type 2 diabetes. For this purpose, we used the Japanese-American Community Diabetes Study (JACDS) cohort, which contains a large number of individuals for whom anthropometric and body composition measurements and assessment of diabetes status have been obtained.

\section{Methods}

Participants The study population consisted of 658 secondand third-generation Japanese-American men and women of $100 \%$ Japanese ancestry who were enrolled in the JACDS. Details about recruitment and enrollment for this study have previously been described [18]. Briefly, participants were chosen from volunteers through community-wide recruitment from 1983 to 1988 and were representative of Japanese-American residents of King County, WA, USA, in terms of age distribution, residential distribution and parental immigration pattern. A comprehensive mailing list and telephone directory that included almost $95 \%$ of the JapaneseAmerican population of King County, WA, was used to identify potential participants. Subjects were followed over 10 years with repeated study measurements. The study protocol was reviewed and approved by the University of Washington Human Subjects Review Committee, and participants provided written consent. For this analysis, we performed a cross-sectional analysis of data obtained at the time individuals entered the study. Since all individuals with diabetes in this population had developed this condition as adults (the youngest age of onset being 31 years), the onset of diabetes occurred well after bone growth had been completed and thus could not have affected limb length.

Measurements All evaluations were performed at the General Clinical Research Center, University of Washington. Anthropomorphic variables were measured with the participants wearing shorts and hospital slippers. Subjects were weighed on a digital recording scale, to the nearest one-hundredth of a kilogram. Height was measured to the nearest tenth of a centimetre. Total arm length was defined as the distance in centimetres between the superior border of the acromion process and the tip of the third finger when the arm and hand were fully extended. Upper arm length was the distance between the head of the radius and the superior border of the acromion process, and forearm length was that from the head of the radius to the tip of the lateral styloid. Total leg length was measured from the standing surface to the trochanteric landmark, with lower leg length being defined as the distance from the inferior border of the lateral malleolus to the lower border of the femoral head. All length measurements were taken on the left side of the body using a tape measure.

A $75 \mathrm{~g}$ OGTT was performed in the morning after a $10 \mathrm{~h}$ overnight fast. Diabetes was diagnosed if the fasting glucose was $\geq 7 \mathrm{mmol} / \mathrm{l}$, the $2 \mathrm{~h}$ value was $\geq 11.1 \mathrm{mmol} / \mathrm{l}$ [19] or individuals were taking oral hypoglycaemic medication or insulin. Plasma glucose was assayed by an automated glucose oxidase method. Subjects who developed diabetes in the 10 year follow-up period were classified as non-diabetic at baseline. The comparison group consisted of those individuals without impaired glucose tolerance (IGT), defined as a $2 \mathrm{~h}$ OGTT value between 7.8 and $11.0 \mathrm{mmol} / \mathrm{l}$. All 658 participants successfully completed an OGTT, and hence this information was available for all individuals in the current analysis.

A single $1 \mathrm{~cm}$ abdominal computed tomography slice was obtained at the level of the umbilicus to determine intra-abdominal fat (IAF) area measured within the confines of the transversalis fascia.

Smoking status was defined as current smoker vs former smoker or non-smoker. The family history of diabetes was deemed to be positive when a first-degree relative had known type 2 diabetes.

Statistics Statistical analyses were performed using STATA SE11 (STATA, College Station, TX, USA). Multiple logistic 
regression was used to estimate the OR for having type 2 diabetes in relation to an increase of $1 \mathrm{SD}$ of the different arm length measurements and other continuous variables. Potential confounders that were added into the models as covariates comprised known risk factors for type 2 diabetes, including IAF area and factors related to limb length. The presence of non-linear associations between limb lengths and odds of diabetes was assessed using a polynomial regression approach. The presence of interaction between limb length and a covariate was tested by the insertion of first-order interaction terms in the appropriate models. We calculated the $95 \%$ CI for each OR. A two-sided $p$ value of $<0.05$ was considered statistically significant.

\section{Results}

Out of the 658 individuals entered into this analysis, 145 had type 2 diabetes. Because 194 participants had IGT, the remaining 319 participants were classified as the comparison population, making the total sample size for analysis 464. Baseline characteristics by diabetes status and sex are shown in Table 1. Compared with those without diabetes, men and women with type 2 diabetes differed significantly in terms of mean age, weight, height, BMI, IAF area, upper arm length, and (in men only) total arm length and total and lower leg length.

Analyses examining whether potential confounders were associated with both dependent (diabetes) and independent (arm length, leg length and height) variables were performed. Age, weight, IAF area, family history of diabetes and smoking status were significantly associated with both $(p<0.05)$. In addition, sex and height were included in multivariable models because of their associations with limb length.

When controlling for explanatory and confounding variables (age, sex, IAF area, height, weight, smoking status and family history of diabetes) using multivariable logistic regression models, a number of associations between arm length measurements and diabetes became apparent (Table 2). Total arm length (OR $0.49,95 \%$ CI $0.29,0.84$ ) and upper arm length (OR $0.56,95 \%$ CI $0.36,0.87$ ) were inversely related to diabetes, whereas forearm length was positively associated with diabetes (OR 1.24; 95\% CI 0.93, 1.65). Total leg length, lower leg length and height did not show a statistically significant association with diabetes after adjustment for potential confounders (age, sex, IAF area, weight, smoking status and family history of diabetes) (Table 3). There were no statistically significant interactions between the different limb length measurements and any of the covariates shown in the fully
Table 1 Baseline characteristics of study participants subdivided by sex and diabetes status

\begin{tabular}{|c|c|c|c|c|}
\hline $\begin{array}{l}\text { Table } 1 \text { Baseline characteristics } \\
\text { of study participants subdivided } \\
\text { by sex and diabetes status }\end{array}$ & Characteristic & $\begin{array}{l}\text { Without type } 2 \\
\text { diabetes }(n=319)\end{array}$ & $\begin{array}{l}\text { With type } 2 \\
\text { diabetes }(n=145)\end{array}$ & $p$ value \\
\hline & Men & $n=169$ & $n=88$ & \\
\hline & Age (years) & $49.3 \pm 11.9$ & $60.9 \pm 7.2$ & $<0.001$ \\
\hline & Weight $(\mathrm{kg})$ & $70.2 \pm 8.9$ & $73.3 \pm 10.5$ & 0.017 \\
\hline & Height $(\mathrm{cm})$ & $168.4 \pm 5.7$ & $166.7 \pm 6.7$ & 0.029 \\
\hline & BMI $\left(\mathrm{kg} / \mathrm{m}^{2}\right)$ & $24.7 \pm 2.7$ & $26.3 \pm 2.9$ & $<0.001$ \\
\hline & IAF area $\left(\mathrm{cm}^{2}\right)$ & $83.7 \pm 46.2$ & $133.2 \pm 54.2$ & $<0.001$ \\
\hline & Total arm length $(\mathrm{cm})$ & $71.9 \pm 3.0$ & $69.8 \pm 5.3$ & $<0.001$ \\
\hline & Upper arm length $(\mathrm{cm})$ & $30.7 \pm 1.7$ & $29.8 \pm 1.9$ & 0.023 \\
\hline & Forearm length $(\mathrm{cm})$ & $20.7 \pm 2.1$ & $20.5 \pm 2.2$ & 0.407 \\
\hline & Total leg length $(\mathrm{cm})$ & $85.4 \pm 4.3$ & $87.3 \pm 4.7$ & 0.002 \\
\hline & Lower leg length $(\mathrm{cm})$ & $36.9 \pm 2.0$ & $36.4 \pm 2.3$ & 0.049 \\
\hline & Women & $n=150$ & $n=57$ & \\
\hline & Age (years) & $50.4 \pm 12.2$ & $62.2 \pm 8.3$ & $<0.001$ \\
\hline & Weight $(\mathrm{kg})$ & $54.6 \pm 7.4$ & $57.7 \pm 9.3$ & 0.018 \\
\hline & Height $(\mathrm{cm})$ & $155.2 \pm 5.4$ & $152.3 \pm 4.6$ & 0.002 \\
\hline & BMI $\left(\mathrm{kg} / \mathrm{m}^{2}\right)$ & $22.6 \pm 2.9$ & $24.7 \pm 3.4$ & $<0.001$ \\
\hline & IAF area $\left(\mathrm{cm}^{2}\right)$ & $58.2 \pm 40.0$ & $118.3 \pm 49.8$ & $<0.001$ \\
\hline & Total arm length $(\mathrm{cm})$ & $64.6 \pm 3.5$ & $63.7 \pm 2.6$ & 0.127 \\
\hline & Upper arm length $(\mathrm{cm})$ & $27.4 \pm 1.9$ & $26.8 \pm 1.9$ & 0.024 \\
\hline & Forearm length $(\mathrm{cm})$ & $18.6 \pm 1.2$ & $18.6 \pm 1.8$ & 0.947 \\
\hline & Total leg length $(\mathrm{cm})$ & $75.7 \pm 4.1$ & $75.7 \pm 4.1$ & 0.942 \\
\hline Data are means \pm SD unless & Lower leg length $(\mathrm{cm})$ & $32.9 \pm 1.9$ & $32.8 \pm 1.7$ & 0.493 \\
\hline
\end{tabular}


Table 2 ORs $(95 \% \mathrm{CI})$ of prevalent diabetes for a 1-SD increase in total arm length, upper arm length and forearm length, adjusted for possible explanatory and confounding factors

\begin{tabular}{|c|c|c|c|c|c|c|}
\hline \multirow[t]{2}{*}{ Covariates in the model } & \multicolumn{2}{|l|}{ Total arm length } & \multicolumn{2}{|l|}{ Upper arm length } & \multicolumn{2}{|l|}{ Forearm length } \\
\hline & $\begin{array}{l}\text { OR for arm length } \\
\text { measurement }\end{array}$ & $95 \% \mathrm{CI}$ & $\begin{array}{l}\text { OR for arm length } \\
\text { measurement }\end{array}$ & $95 \% \mathrm{CI}$ & $\begin{array}{l}\text { OR for arm length } \\
\text { measurement }\end{array}$ & $95 \% \mathrm{CI}$ \\
\hline None & $0.82 *$ & $0.68,0.99$ & $0.80 *$ & $0.66,0.97$ & 1.01 & $0.82,1.23$ \\
\hline Age & 0.98 & $0.79,1.21$ & 1.00 & $0.81,1.25$ & $1.27 *$ & $1.02,1.58$ \\
\hline Age, sex & 0.74 & $0.55,1.01$ & 0.79 & $0.59,1.05$ & 1.19 & $0.94,1.53$ \\
\hline Age, sex, weight & $0.47 * * *$ & $0.32,0.69$ & $0.50 * * *$ & $0.36,0.69$ & 1.05 & $0.82,1.35$ \\
\hline Age, sex, weight, IAF area & $0.54 * *$ & $0.36,0.81$ & $0.58^{*}$ & $0.41,0.82$ & 1.17 & $0.89,1.53$ \\
\hline Age, sex, weight, IAF area, height & $0.52 * *$ & $0.32,0.85$ & $0.56^{*}$ & $0.37,0.85$ & 1.23 & $0.94,1.62$ \\
\hline $\begin{array}{l}\text { Age, sex, weight, IAF area, } \\
\text { height, family history }\end{array}$ & $0.49 * *$ & $0.29,0.84$ & $0.55^{*}$ & $0.36,0.86$ & 1.26 & $0.95,1.68$ \\
\hline $\begin{array}{l}\text { Age, sex, weight, IAF area, } \\
\text { height, family history, smoking }\end{array}$ & $0.49 * *$ & $0.29,0.84$ & $0.56^{*}$ & $0.36,0.87$ & 1.24 & $0.93,1.65$ \\
\hline
\end{tabular}

$* p<0.05, * * p<0.01, * * * p<0.001$

adjusted models in Tables 2 and 3 (sex $\times$ total arm length, $p=$ 0.126 ; sex $\times$ upper arm length, $p=0.492$; sex $\times$ forearm length, $p=0.358$; sex $\times$ total leg length, $p=0.223$; sex $\times$ lower leg length, $p=0.157$ and sex $\times$ height, $p=0.598)$. The quadratic transformations of the limb length measurements were not significant in the multivariable models, so a linear relation can therefore be assumed.

Even though there was no significant interaction between sex and arm length measurements, sex-specific analyses for the associations between arm lengths and diabetes were performed. The sex-specific findings in adjusted models are shown in Fig. 1. The associations between upper and total arm length and diabetes odds are of greater magnitude in men than women.

A sensitivity analysis was performed that excluded individuals who had diabetes at baseline or who developed diabetes in the 10-year follow-up period. This analysis yielded similar results to those shown in Tables 2 and 3.
The analyses in Tables 2 and 3 were re-run after including individuals with IGT in the comparison group, and these results were nearly identical to those described above.

\section{Discussion}

We have shown that, after adjustment for confounding factors, total and upper arm lengths are inversely associated with prevalence of diabetes in Japanese-American individuals. Forearm length, total leg length, lower leg length and height were not associated with diabetes. No significant interaction was seen between limb length and sex in the prediction of diabetes prevalence, although differences in the magnitudes of these associations by sex did appear when a sex-specific analysis was conducted. Given the nonsignificance of the sex-limb length interactions, we believe the evidence does not therefore strongly support a difference

Table 3 ORs (95\% CI) of prevalent diabetes for a 1-SD increase in total leg length, lower leg length and height, adjusted for possible explanatory and confounding factors

\begin{tabular}{|c|c|c|c|c|c|c|}
\hline \multirow[t]{2}{*}{ Covariates in the model } & \multicolumn{2}{|l|}{ Total leg length } & \multicolumn{2}{|l|}{ Lower leg length } & \multicolumn{2}{|l|}{ Height } \\
\hline & $\begin{array}{l}\text { OR for leg length } \\
\text { measurement }\end{array}$ & $95 \% \mathrm{CI}$ & $\begin{array}{l}\text { OR for leg length } \\
\text { measurement }\end{array}$ & $95 \% \mathrm{CI}$ & $\begin{array}{l}\text { OR for } \\
\text { height }\end{array}$ & $95 \% \mathrm{CI}$ \\
\hline None & $1.33 * *$ & $1.09,1.62$ & 0.97 & $0.79,1.17$ & 0.89 & $0.73,1.08$ \\
\hline Age & $1.25 *$ & $1.02,1.54$ & 1.19 & $0.96,1.49$ & 1.19 & $0.95,1.48$ \\
\hline Age, sex & 1.17 & $0.83,1.66$ & 1.04 & $0.77,1.42$ & 0.99 & $0.70,1.42$ \\
\hline Age, sex, weight & 0.88 & $0.61,1.29$ & 0.74 & $0.52,1.03$ & $0.52 * *$ & $0.34,0.79$ \\
\hline Age, sex, weight, IAF area & 1.10 & $0.74,1.65$ & 0.96 & $0.67,1.39$ & 0.73 & $0.46,1.15$ \\
\hline Age, sex, weight, IAF area, family history & 1.12 & $0.73,1.70$ & 0.97 & $0.66,1.43$ & 0.75 & $0.47,1.22$ \\
\hline Age, sex, weight, IAF area, family history, smoking & 1.07 & $0.70,1.64$ & 0.94 & $0.64,1.38$ & 0.72 & $0.44,1.17$ \\
\hline
\end{tabular}

$* p<0.05, * * p<0.01$ 

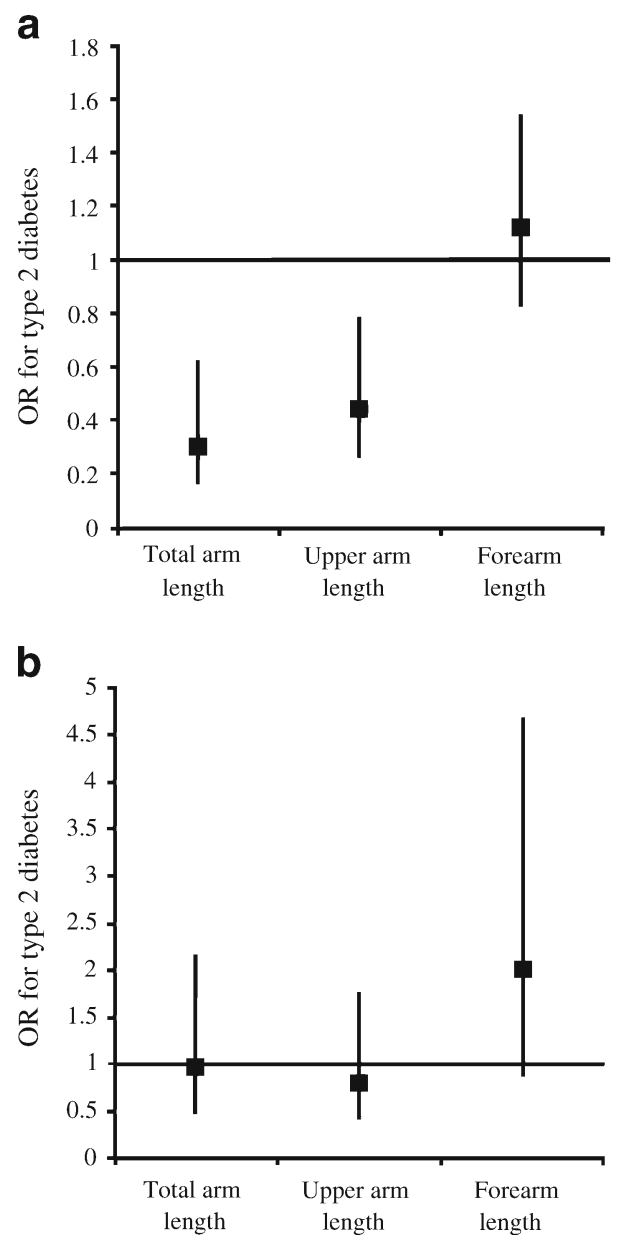

Fig. 1 ORs of diabetes by arm measurements in (a) men $(n=257)$ and (b) women $(n=207)$. ORs with $95 \% \mathrm{CI}$ for diabetes are illustrated per $1 \mathrm{SD}$ increase in arm measurements, corrected for age, IAF area, height, weight, smoking status and family history

in the associations between limb length and diabetes prevalence by sex. To the best of our knowledge, this is the first study in humans to report that shorter arm length is independently associated with a higher prevalence of diabetes.

Our findings are in keeping with suggestions in the limited literature hypothesising that arm length may be associated with diabetes. A shorter demi-arm span (measured from the sternal midline to the web space between the middle and fourth fingers) has been shown not to be associated with diabetes [2]. However, in that study, diabetes was defined based on self-reporting, which may have resulted in a misclassification of diabetes status without oral glucose tolerance testing to confirm this diagnosis, and furthermore may have had limited statistical power as only 24 individuals with this disorder were included in the analysis. In an animal study using the Goto-Kakizaki rat model of type 2 diabetes, those animals with diabetes had shorter humerus lengths than those without [20]. Finally, arm length has been shown to be inversely associated with dementia (both Alzheimer's disease and vascular dementia), a condition that appears to be associated with the early life environment, as may also be the case with type 2 diabetes as postulated in the thrifty phenotype hypothesis [17, 21].

Although not as extensively studied as leg length, arm length has been shown to be associated with environmental conditions during early childhood $[16,17]$ and can therefore be used as a marker of early exposures and deprivation. The mechanism linking environmental conditions, arm length and diabetes would appear to be in line with the thrifty phenotype hypothesis [12]. According to this hypothesis, poor nutrition in utero and/or in the early childhood period leads to impaired development of the endocrine pancreas and thus an increased susceptibility to developing diabetes in later life owing to limited pancreatic beta cell insulin secretory capacity. Supporting this hypothesis is the finding that there is a decrease in number of fetal pancreatic beta cells in human pregnancies complicated by intrauterine growth reduction, often caused by environmental factors (such as smoking, infections and maternal diet) [22, 23]. Our finding that adult total arm length is inversely associated with diabetes provides further indirect support for the hypothesis that environmental factors during the fetal and childhood period are associated with the development of diabetes.

Different studies have demonstrated an association between leg length, height and diabetes [1, 3, 5]. Interestingly, we were not able to find such a relation. However, none of these studies focused on Japanese-American individuals, who are known to have a different body composition from white Americans [24]. Moreover, heterogeneity between races with regard to associations between health outcomes and body proportions has been shown before by Weitzman et al., who reported that leg length is inversely linked to diabetes in white individuals but not African-Americans [5].

The different body composition of Japanese and white individuals might be a limitation of our study. It has been shown that Japanese college students have relatively short arm to height ratios and thigh lengths compared with their white American counterparts [24]. Even though our study clearly shows the inverse association of arm length and diabetes in Japanese-Americans, this may not be generalisable to other ethnic groups.

A second limitation is that we could not correct for possible differences in socioeconomic status or level of education, as these variables were not recorded. It is thought, however, that social status was quite similar in this homogenous study cohort. Finally, we did not determine the islet cell antibody status of participants in the study and therefore cannot exclude the fact that some individuals may have had type 1 diabetes. However, given that Japanese people have a very low risk of diabetes compared with other ethnic groups [25], and also that the youngest age of diabetes onset in our population was 31 years, it is likely that all persons in this analysis with 
diabetes had type 2 disease. Similar results were obtained when the analysis was repeated after excluding the participants who did not have diabetes at baseline but who developed this condition over the 10-year follow-up period.

In conclusion, total and upper arm lengths were inversely associated with prevalence of diabetes, whereas forearm length, height and total and lower leg length were not related to diabetes. Since total arm length is dependent on environmental factors during pregnancy and early childhood, our findings are in keeping with the hypothesis that type 2 diabetes is determined in part by environmental factors in early life. Since height and leg length were related to diabetes in other studies with white participants, this suggests possible ethnic differences in these associations. The relationship between limb lengths and diabetes is more complex than has been previously recognised, and further research is needed to better understand these associations.

Acknowledgements We appreciate the support and cooperation given by the King County Japanese-American Community to the study.

Funding This work was supported by National Institutes of Health Grants DK-31170, HL-49293 and DK-02654, as well as by facilities and services provided by the Diabetes Research Center (DK-17047), Nutrition Obesity Research Center (DK-35816) and General Clinical Research Center (RR-00037) at the University of Washington. The Department of Veterans Affairs and VA Puget Sound Health Care System provided support to EJB and SEK.

Duality of interest The authors declare that there is no duality of interest associated with this manuscript.

Contribution statement MMS analysed the data, drafted and edited the manuscript. EJB, KMU, SS, LAW, DLL, MJMcN, WYF and SEK helped with interpreting the data, contributed to the discussion and reviewed/edited the manuscript. All authors approved the final version.

\section{References}

1. Brown DC, Byrne CD, Clark PM et al (1991) Height and glucose tolerance in adult subjects. Diabetologia 34:531-533

2. Han TS, Hooper JP, Morrison CE, Lean ME (1997) Skeletal proportions and metabolic disorders in adults. Eur J Clin Nutr 51:804-809

3. Lawlor DA, Ebrahim S, Davey SG (2002) The association between components of adult height and type II diabetes and insulin resistance: British Women's Heart and Health Study. Diabetologia 45:1097-1106

4. Liu J, Tan H, Jeynes B (2009) Is femur length the key height component in risk prediction of type 2 diabetes among adults? Diabetes Care 32:739-740

5. Weitzman S, Wang CH, Pankow JS, Schmidt MI, Brancati FL (2010) Are measures of height and leg length related to incident diabetes mellitus? The ARIC (Atherosclerosis Risk in Communities) study. Acta Diabetol 47:237-242

6. Bogin B, Varela-Silva MI (2010) Leg length, body proportion, and health: a review with a note on beauty. Int J Environ Res Public Health 7:1047-1075

7. Leitch I (1951) Growth and health. Br J Nutr 5:142-151

8. Wadsworth ME, Hardy RJ, Paul AA, Marshall SF, Cole TJ (2002) Leg and trunk length at 43 years in relation to childhood health, diet and family circumstances; evidence from the 1946 national birth cohort. Int J Epidemiol 31:383-390

9. Gunnell DJ, Smith GD, Frankel SJ, Kemp M, Peters TJ (1998) Socio-economic and dietary influences on leg length and trunk length in childhood: a reanalysis of the Carnegie (Boyd Orr) survey of diet and health in prewar Britain (1937-39). Paediatr Perinat Epidemiol 12(Suppl 1):96-113

10. Gunnell D, Okasha M, Smith GD, Oliver SE, Sandhu J, Holly JM (2001) Height, leg length, and cancer risk: a systematic review. Epidemiol Rev 23:313-342

11. Kinra S, Sarma KV, Hards M, Smith GD, Ben-Shlomo Y (2011) Is relative leg length a biomarker of childhood nutrition? Long-term follow-up of the Hyderabad Nutrition Trial. Int J Epidemiol 40:1022-1029

12. Hales CN, Barker DJ (1992) Type 2 (non-insulin-dependent) diabetes mellitus: the thrifty phenotype hypothesis. Diabetologia 35:595-601

13. O'Flaherty EJ (1994) Physiologic changes during growth and development. Environ Health Perspect 102(Suppl 11):103-106

14. Yun DJ, Yun DK, Chang YY, Lim SW, Lee MK, Kim SY (1995) Correlations among height, leg length and arm span in growing Korean children. Ann Hum Biol 22:443-458

15. Malina RM, Bouchard C, Bar-Or O (2004) Timing and sequence of changes during adolescence. In: Malina RM, Bouchard C, Bar-Or O (eds) Growth, maturation, and physical activity, 2nd edn. Human Kinetic, Champaign, pp 307-336

16. Ignasiak Z, Slawinska T, Rozek K, Little BB, Malina RM (2006) Lead and growth status of school children living in the copper basin of south-western Poland: differential effects on bone growth. Ann Hum Biol 33:401-414

17. Kim JM, Stewart R, Shin IS, Yoon JS (2003) Limb length and dementia in an older Korean population. J Neurol Neurosurg Psychiatry 74:427-432

18. Fujimoto WY, Leonetti DL, Kinyoun JL et al (1987) Prevalence of diabetes mellitus and impaired glucose tolerance among secondgeneration Japanese-American men. Diabetes 36:721-729

19. American Diabetes Association (2003) Report of the expert committee on the diagnosis and classification of diabetes mellitus. Diabetes Care 26(Suppl 1):S5-S20

20. Ahmad T, Ohlsson C, Saaf M, Ostenson CG, Kreicbergs A (2003) Skeletal changes in type-2 diabetic Goto-Kakizaki rats. J Endocrinol 178:111-116

21. Huang TL, Carlson MC, Fitzpatrick AL, Kuller LH, Fried LP, Zandi PP (2008) Knee height and arm span: a reflection of early life environment and risk of dementia. Neurology 70:1818-1826

22. Hendrix N, Berghella V (2008) Non-placental causes of intrauterine growth restriction. Semin Perinatol 32:161-165

23. Van Assche FA, de Prins F, Aerts L, Verjans M (1977) The endocrine pancreas in small-for-dates infants. Br J Obstet Gynaecol 84:751-753

24. Nakanishi Y, Nethery V (1999) Anthropometric comparison between Japanese and Caucasian American male university students. Appl Human Sci 18:9-11

25. Kawasaki E, Matsuura N, Eguchi K (2006) Type 1 diabetes in Japan. Diabetologia 49:828-836 